Palliative and Supportive Care, 2021, 1-11. doi:10.1017/S1478951521000626

\title{
Development and Preliminary Evaluation of EMPOWER for Surrogate Decision-Makers of Critically Ill Patients
}

Wendy G. Lichtenthal, ${ }^{1,2}$ Martin Viola, ${ }^{2}$ Madeline Rogers, ${ }^{1,2}$ Kailey E. Roberts, ${ }^{1,3}$ Lindsay Lief, ${ }^{2}$ Christopher Cox,${ }^{4}$ Chris R. Brewin, ${ }^{5}$ Jiehui Cici Xu, ${ }^{2}$ Paul Maciejewski, ${ }^{2}$ Cynthia X. Pan, ${ }^{2}$ Taylor Coats, ${ }^{1}$ Daniel J. Ouyang, ${ }^{2}$ Shayna Rabin, ${ }^{2,3}$ Susan C. Vaughan, ${ }^{7}$ William Breitbart, ${ }^{1,2}$ Marjorie E. Marenberg, ${ }^{8} \&$ Holly G. Prigerson ${ }^{2}$

${ }^{1}$ Memorial Sloan Kettering Cancer Center, New York, New York

${ }^{2}$ Weill Cornell Medicine, New York, New York

${ }^{3}$ Yeshiva University, Bronx, New York

${ }^{4}$ Duke University School of Medicine, Durham, North Carolina

${ }^{5}$ University College London, London, England

${ }^{6}$ NewYork-Presbyterian Queens, Flushing, New York

${ }^{7}$ Columbia University Irving Medical Center, New York, New York

${ }^{8}$ Corporal Michael J Crescenz VA Medical Center, Philadelphia, Pennsylvania

\section{Corresponding Author:}

Wendy G. Lichtenthal, PhD, FT

Memorial Sloan Kettering Cancer Center

321 East $61^{\text {st }}$ Street, New York, New York 10065

Phone: (646) 608-8204; Email: lichtenw@ mskcc.org 
EMPOWER FOR SURROGATES OF CRITICALLY ILL PATIENTS

\begin{abstract}
Objective: The objectives of this study were to develop and refine EMPOWER (Enhancing and Mobilizing the POtential for Wellness and Resilience), a brief manualized cognitive-behavioral, acceptance-based intervention for surrogate decision-makers of critically ill patients and to evaluate its preliminary feasibility, acceptability, and promise in improving surrogates' mental health and patient outcomes.
\end{abstract}

Method: Part 1 involved obtaining qualitative stakeholder feedback from 5 bereaved surrogates and 10 critical care and mental health clinicians. Stakeholders were provided with the manual and prompted for feedback on its content, format, and language. Feedback was organized and incorporated into the manual which was then re-circulated until consensus.

In Part 2, surrogates of critically ill patients admitted to an intensive care unit (ICU) reporting moderate anxiety or close attachment were enrolled in an open trial of EMPOWER. Surrogates completed 6, 15-20 minute modules, totaling 1.5-2 hours. Surrogates were administered measures of peritraumatic distress, experiential avoidance, prolonged grief, distress tolerance, anxiety, and depression at pre-intervention, post-intervention, and at one-month and three-month follow-up assessments.

Results: Part 1 resulted in changes to the EMPOWER manual, including reducing jargon, improving navigability, making EMPOWER applicable for a range of illness scenarios, rearranging the modules, and adding further instructions and psychoeducation.

Part 2 findings suggested that EMPOWER is feasible, with $100 \%$ of participants completing all modules. Acceptability of EMPOWER appeared strong, with high ratings of effectiveness and helpfulness $(M=8 / 10)$. Results showed immediate post-intervention improvements in anxiety $(d=-0.41)$, peritraumatic distress $(d=-0.24)$, and experiential avoidance $(d=-0.23)$. At the three- 
month follow-up assessments, surrogates exhibited improvements in prolonged grief symptoms $(d=-0.94)$, depression $(d=-0.23)$, anxiety $(d=-0.29)$, and experiential avoidance $(d=-0.30)$. Significance of results: Preliminary data suggest EMPOWER is feasible, acceptable, and associated with notable improvements in psychological symptoms among surrogates. Future research should examine EMPOWER with a larger sample in a randomized controlled trial.

Key Words: critical care, surrogate decision-making, intensive care unit, intervention, grief 
EMPOWER FOR SURROGATES OF CRITICALLY ILL PATIENTS

\section{Introduction}

Research has repeatedly shown that surrogate decision-makers of critically ill patients receiving intensive care are at heightened risk of significant psychological distress, including posttraumatic stress disorder (PTSD) and prolonged grief disorder (PGD) (Anderson et al., 2008;

Derry et al., 2020; Greenberg et al., 2021; Kentish-Barnes et al., 2015; Lovell et al., 2015; Rodriguez Villar et al., 2012; Siegel et al., 2008; Wright et al., 2010). Involvement in making end-of-life decisions appears to be a particularly significant source of stress (Azoulay et al., 2005). This is largely due to the intense emotional conflict surrogates frequently experience, as their wish to make decisions that are in accordance with the patient's values may be at odds with their fear of feeling responsible for the patient's well-being and death, their desire to preserve the patient's life, and the need to protect the welfare of their family (Schenker et al., 2012). Often, intensive care unit (ICU) clinical staff approach surrogates to make life-and-death decisions, such as consenting to Do Not Resuscitate (DNR) orders, on short notice and with little mental preparation, exacerbating this internal conflict. Surrogates may be in a state of shock about patients' deteriorating health, grief-stricken over the prospect of their loved ones' impending deaths, and coping with trauma-provoking patient suffering and medical realities in the ICU. Being in such a distressed psychological state understandably can have an impact on a surrogate's decision-making capacity. Thus, guilt, regret, and protracted grief following the patient's death are common (Hickman et al., 2012; Lovell et al., 2015).

There have been several efforts to address the mental health needs of surrogates. However, prior intervention trials have produced mixed results (Carson et al., 2016; Cox et al., 2019; Curtis et al., 2013; Dionne-Odom et al., 2020; Lautrette et al., 2007; White et al., 2018; White et al., 2012). A primary limitation of these clinical trials is that they have targeted mental 
EMPOWER FOR SURROGATES OF CRITICALLY ILL PATIENTS

health outcomes without utilizing explicit mental health interventions. The current proof-ofconcept study aims to address this limitation. We developed and pilot tested a brief mental health

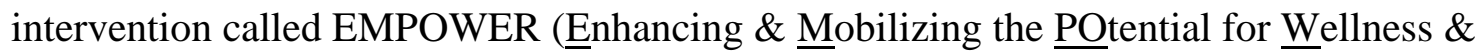
Emotional Resilience), which uses ultra-brief (Sperry \& Binensztok, 2019), evidence-based cognitive-behavioral, acceptance-based techniques to reduce experiential avoidance, grief, anxiety, and peritraumatic distress (Prigerson et al., 2019).

Our conceptual model posits that symptoms of grief, anxiety, traumatic stress, and related maladaptive coping reactions such as dissociation and avoidance, interfere with engaging in value-concordant and empowered end-of-life decision-making (Glick et al., 2018). We highlight the role in coping of experiential avoidance, which is the natural tendency to avoid unpleasant feelings and consideration of negative outcomes (Gamez et al., 2014; Gamez et al., 2011; Plumb et al., 2004) and which has been associated with PTSD and PGD (Bishop et al., 2018; Marx \& Sloan, 2005a; Serrano-Ibanez et al., 2021; Williams et al., 2019). There are many subtle ways avoidance may manifest for surrogates. As the prospect of losing the patient weighs on them, they may push for more aggressive care, attempting to avoid their grief. Faced with the prospect of the patient suffering, they may seek reassurance from clinicians, attempting to avoid feelings of guilt. Fearful of making the "wrong" decision, they may avoid engaging in goals of care discussions and end-of-life decisions. This avoidance is likely to be detrimental, as advance care planning and goals of care discussions have been associated with higher quality, less aggressive, and more value-consistent end-of-life care, as well as better patient quality of life (Mack et al., 2010). Both of these predict better bereavement adjustment of the caregiver (Garrido \& Prigerson, 2014; Wright et al., 2008). 
The ability of surrogates to engage in end-of-life decision-making on the patient's behalf relies on them to be emotionally "present" and thinking clearly. EMPOWER aims to reduce surrogates' experiential avoidance and to empower them in their decision-making role (Tunzi, 2012), providing them with tools to cope with distress related to the patient's impending death as well as to adjust following the patient's ICU discharge or death.

Guided by the Stage Model of Behavioral Therapies (Rounsaville et al., 2001), the present study focused on Stage IA (e.g., intervention development and refinement) and had two objectives: 1) to develop and refine EMPOWER using feedback from bereaved surrogates and from expert critical care and mental health clinicians; and 2) to determine preliminary feasibility, acceptability, and effects of EMPOWER on surrogate mental health and patient outcomes.

\section{Methods}

\section{Study Design and Procedures}

This Institutional Review Board-approved study (Weill Cornell Medicine IRB \#1610017622; Clinicaltrials.gov Registration \# NCT03276550) involved refinement of the EMPOWER intervention manual (Part 1) followed by a single-arm pilot trial of EMPOWER (Part 2).

Part 1 used a modified Delphi approach that involved gathering opinions from experts, keeping feedback anonymous, identifying and summarizing feedback themes, and circulating modifications back to experts until consensus is reached (de Meyrick, 2003). Key informants were nominated by targeted sampling (de Meyrick, 2003) of ICU and mental health clinicians, ensuring representation from different training and specialties and bereaved surrogates of patients who had been admitted to the ICU. Consented surrogates and clinicians were provided with a copy of the EMPOWER intervention manual and a survey primarily conducted by interview, which included 
prompts to elicit structured feedback on its content, format, and language. Interviews were audiorecorded and transcribed using a professional service. Following analysis of round one feedback, key informants were provided with an updated manual to offer any additional feedback. Key informants received $\$ 50$ for their participation.

Part 2 was an open trial of EMPOWER implemented in the ICU of an urban academic medical center. Individuals were eligible if they were the healthcare proxy or surrogate of a noncommunicative, critically ill patient, as indicated in the patient's medical record or by the ICU medical team. Patients had to be at least age 21 or older, lack of decisional capacity (e.g., on ventilator, unconscious, or cognitively impaired rendering them unable to talk), admitted to an ICU or step-down unit during their current hospitalization, and considered by the ICU attending or fellow to be near the end of life (patients whose ICU physicians or fellows would not be surprised if they did not survive more than 3 months; Haydar et al., 2019). Surrogate decisionmakers had to be English-speaking, report a very close attachment to the patient (a summed score of at least 8 on two items from the Partner Dependence Scale) (Johnson et al., 2006; Johnson et al., 2007), and be at least moderately anxious (greater than 5 on either anxiety item of the McGill Quality of Life Scale) (Cohen et al., 1995). ${ }^{1}$ Screening scores were selected based on pilot data indicating anxiety and attachment issues are key risks for poor coping among caregivers (Garrido \& Prigerson, 2014; Higgins et al., 2015; Prigerson et al., 2009; Wright et al., 2010). Exclusion criteria included current suicidal ideation.

Surrogates were identified by reviewing the ICU census with the ICU clinical staff several times a week to identify patients lacking decisional capacity. After obtaining permission from

\footnotetext{
${ }^{1}$ For the first seven participants, surrogates were eligible if they had a Partner Dependency Score $>8$ or reported at least a 5 on a 1-10 scale of any of the following emotions, with 1 being "not at all" and 10 being "extremely": upset, frustrated, angry, stressed, anxious, confused, or worried. For the final three participants, the distress item was changed to a score of >5 on either McGill Quality of Life anxiety question, rated from 0 to 10 .
} 
attending physicians, research assistants approached the surrogate in the ICU. If the surrogate was interested and eligible, informed consent was obtained. Access to patients' charts was permitted through a Health Insurance Portability and Accountability Act (HIPAA) waiver.

Surrogates were assessed with self-report measures pre-intervention/baseline (Time 1 [T1]), post-intervention (within a week of the surrogate's completion of the baseline assessment) (T2), on month post-baseline (T3), and three months post-baseline (T4). They were also invited to complete a qualitative exit interview to provide feedback on EMPOWER. Patient outcomes included ACP and intensity of care. Participants received \$25 per assessment completed, for a maximum of $\$ 100$. The EMPOWER intervention was delivered by the lead intervention developer, WGL, who is a licensed clinical psychologist, for the first four cases. In preparation for a subsequent feasibility pilot randomized controlled trial, additional interventionists were thoroughly trained through didactics and review of recordings of the initial cases. Interventionists included a Master's level advanced clinical psychology doctoral student, an experienced licensed social worker, and a more recently licensed social worker. All four interventionists had prior experience working with family caregivers and bereaved populations.

\section{Intervention and Conceptual Model Description}

EMPOWER incorporates evidence-based cognitive-behavioral approaches (Birur et al., 2016; Boelen et al., 2007; Bryant et al., 2014; Bryant et al., 2008; Bryant et al., 2003; Gartlehner et al., 2013; Litz et al., 2014), acceptance-based principles to build distress tolerance (Kelly et al., 2015; McLean \& Follette, 2016; Orsillo \& Batten, 2005; Walser \& Westrup, 2007), and grief therapy techniques (Neimeyer, 2012, 2016) to reduce experiential avoidance and symptoms of anxiety, grief, and traumatic stress. The program targets individuals reporting distress and at risk of poor outcomes in the longer-term. It consists of 6 discrete $\sim 15$-minute modules delivered 
flexibly in a setting that is frequently prone to multiple interruptions and crises such as the ICU. The 6 modules may be done in a single session or in parts over the course of 2 to 3 days, though this varies and may take longer, depending on the surrogate's preference and availability.

The intervention uses empathic support, psychoeducation, and experiential exercises, and is tailored to the most pressing and distressing challenges that the surrogate reports, be they fears of losing the patient, worries about decision-making, concerns about family, or a combination of stressors. Table 1 provides an overview of the intervention content and structure. EMPOWER begins in Module 1 with an assessment of the surrogate's most significant sources of distress and provision of empathic support. In Module 2, the surrogate engages in breathing retraining, grounding exercises, and mindfulness meditation to address acute emotional and physiological stress responses (e.g., symptoms of hyperarousal and/or dissociation) in order to facilitate processing of the subsequent psychoeducation. The surrogate is taught how to use these tools to manage symptoms and assist with processing information provided by the patient's medical team moving forward.

In Module 3, they are provided with psychoeducation about experiential avoidance and the cognitive-behavioral model to help facilitate emotional processing (Foa et al., 2007). They are taught how experiential avoidance can manifest in many ways - through the pursuit of aggressive care of the patient, avoidance of making significant decisions, ruminative worry, and/or reassurance-seeking — and how such behaviors reflect the individual's efforts, whether conscious or not, to "get away", or flee, from the difficult cognitions and emotions. Surrogates are taught about how such avoidance is negatively reinforcing-bringing short-term respite, but paradoxically maintaining their distress. In Module 4, acceptance-based principles and coping strategies are reviewed. The surrogate's ability to tolerate distress in real-time and throughout the 
EMPOWER encounter are highlighted to help increase acceptance of these aversive states and foster self-compassion (Orsillo \& Batten, 2005; Walser \& Westrup, 2007).

EMPOWER targets key attachment issues related to grief and any decision-making challenges in Module 5. This module also reviews psychoeducation and discusses strategies for preventing regrets. It invites an imaginal dialogue with the patient to garner the patient's support in the surrogate's struggle to consider the patient's wishes and values, and to facilitate quality decision-making and empowerment (Cox et al., 2015; Tunzi, 2012). The intervention concludes in Module 6 with a review of the key EMPOWER principles and coping rehearsal for anticipated stressful situations. Two booster calls are conducted (two and four weeks later) to review the key principles of EMPOWER, to discuss successes and challenges applying the coping strategies in real-life scenarios, and to engage in coping rehearsal for anticipated stressful situations. Since in many cases the patient has died prior to one of the booster calls, this call often provides acute bereavement support and reviews how to apply the EMPOWER principles in coping with post-loss grief and bereavement.

EMPOWER focuses largely on exercises that involve carefully titrated exposure to distress during the intervention. Importantly, however, interventionists must be careful to work within the surrogate's "therapeutic window"; that is, to adequately activate the individual's emotions without exceeding their capacity to tolerate distress (Briere \& Lanktree, 2013). The interventionist pays careful attention to the surrogate's ability to regulate affect so as to avoid retraumatizing them. The focus on providing individually-tailored tools for higher-risk individuals distinguishes EMPOWER from interventions like critical incident stress debriefing (Gartlehner et al., 2013; Mitchell \& Everly, 1995). Ultimately, EMPOWER aims to help surrogates make difficult decisions by building tolerance for painful feelings and negative intrusive thoughts, and 
EMPOWER FOR SURROGATES OF CRITICALLY ILL PATIENTS

by minimizing future chronic avoidance (e.g., of emotional triggers), so that normative acute stress and grief responses do not escalate into pathological reactions like PTSD and PGD (Bishop et al., 2018; Marx \& Sloan, 2005a; Serrano-Ibanez et al., 2021; Williams et al., 2019). The intervention manual also notes adaptations for various cultural and ethnic populations and the importance of cultural competence in delivering EMPOWER to diverse surrogate groups.

\section{Assessment of Feasibility and Acceptability}

We assessed the proportion of surrogates approached for the open trial who a) consented, b) declined participation, and c) were ineligible. We also assessed delivery of EMPOWER by recording the number of modules completed and reasons not completed. Feasibility of a) recruitment, b) implementation, c) measurement, and d) retention were examined. Surrogate satisfaction at T2 and attrition at T4 were used to evaluate acceptability. Part 2 participants were also invited to complete a qualitative exit interview about their experience with EMPOWER and to provide any additional feedback about acceptability and to further refine the intervention.

\section{Self-Report Measures}

Demographic and background information. Surrogates self-reported demographic information during the baseline interview. Demographic information for patients, as well as medical information including DNR order completion, intubation, extubation, and withdrawal of life-sustaining care were obtained through medical chart abstraction.

Psychological outcomes. Peritraumatic distress, the primary outcome, was measured at T1 and T2 by the Peritraumatic Distress Inventory (PDI), a reliable $(\alpha=0.76)$ and valid 13-item test that measures the extent to which an individual experienced distress at the time of a critical incident event and in the subsequent minutes or hours (Brunet et al., 2001; Bunnell et al., 2018). By inference, the event corresponded to the ICU stay of the patient, and to remove any 
ambiguity, this was made explicit for the final participant. Due to their lack of relevance in the ICU setting, items 4 and 7 of the PDI were not administered to participants, yielding a modified 11-item version, with scores ranging from 0 to 44 , with higher scores representing greater peritraumatic distress. Symptoms of intrusion and avoidance, often used as an indicator of PTSD, were measured at T2, T3, and T4 using the reliable $(\alpha=0.79-0.94)$ Impact of Event Scale-Revised (Weiss \& Marmar, 1996). The first item of this measure was not administered to participants, leaving a total of 21 items, with scores ranging from 0 to 88 , and higher scores representing greater PTSD symptomology. Instructions were modified to specify that participants were to respond to the items regarding "stressful events in the ICU" rather than "stressful life events" as is detailed in the original instructions (Weiss \& Marmar, 1996). The first nine participants were asked to specify an index event in the ICU, whereas the final participant was asked to respond based on the ICU stay in general.

Experiential avoidance was measured by the Brief Experiential Avoidance Questionnaire (BEAQ) (Gamez et al., 2014), a 15-item measure assessing 6 dimensions of experiential avoidance that has demonstrated good internal consistency. Scores range from 15 to 90, with higher scores representing greater experiential avoidance. Anticipatory grief was measured by the 12-item PG-12 (Prigerson et al., 2009; Prigerson et al., 2008; Zhang et al., 2006), and postloss PGD symptom severity was assessed by the widely used, valid, 13-item PG-13 (Prigerson et al., 2009; Prigerson et al., 2008; Zhang et al., 2006). Combined scores on these measures were used to index pre- or post-loss grief intensity, with scores ranging from 11 to 55, and higher scores representing greater grief intensity.

For the first three participants enrolled, anxiety and depression was measured by the Hospital Anxiety and Depression Scale (HADS), a valid and reliable 14-item measure of anxiety 
and depression used in both hospital and community settings (Zigmond \& Snaith, 1983). The measure has demonstrated reliability in caregivers ( $\alpha=0.85$ for anxiety; $\alpha=0.84$ for depression) (Gough \& Hudson, 2009). Scores for both anxiety and depression subscales range from 0 to 21 , with greater scores representing greater symptoms. For the remaining seven participants, anxiety was measured using the Generalized Anxiety Disorder-7 (GAD-7), a valid and reliable 7-item measure of generalized anxiety symptoms (scores ranging from 0 to 21) (Spitzer et al., 2006), and depression was measured with the widely used 9-item Patient Health Questionnaire-9 (PHQ9), with scores ranging from 0 to 27 (Kroenke et al., 2001).

Distress tolerance was indexed by the summed score of items $1,2,8$ and 9 of the 14item Distress Tolerance Scale (DTS), which assesses an individual's ability to endure negative emotional states (Simons \& Gaher, 2005). The summed score of these items can range from 0 to 20, with greater scores representing greater ability to tolerate distress. Decision-making selfefficacy was measured by the Family Decision-Making Self-efficacy Scale: Unconscious Patient Scenario (FDMSS), a 13-item valid and reliable assessment of confidence of family members in their ability to make decisions with or for a terminally ill loved one (Nolan et al., 2009). Using a modified response scale of 1 to 6 , scores ranged from 13 to 78, with higher scores representing greater self-efficacy. Satisfaction with and helpfulness of the EMPOWER components was measured by a Post-Intervention Satisfaction Questionnaire (PISQ), an assessment of helpful treatment components and satisfaction with the intervention. All participants received a single categorical item inquiring about treatment length. The final seven participants were asked to rate the helpfulness and effectiveness of the EMPOWER intervention on a Likert-style scale where 0 represented "not at all" and 10 represented "extremely." These participants also rated how helpful EMPOWER was on 4 ICU-related domains (i.e. "It helped me to think through what the patient 
EMPOWER FOR SURROGATES OF CRITICALLY ILL PATIENTS

wanted," "It helped make me less stressed") on a similar Likert-style 0 to 10 scale, where 0 represented "not at all helpful" and 10 represented "extremely helpful."

\section{Data Analysis}

Part 1 key informant interviews were transcribed and content analyzed, a well-established, systematic qualitative analysis approach in health research (Morse, 1994), to identify themes from participants' narratives. We followed Morse's (1994) guidelines for conducting rigorous qualitative research (e.g., consensus coding, thematic saturation) using Atlas.ti software. Coding of feedback was overseen by KER and WGL, who have extensive experience in qualitative methods for intervention development. A preliminary codebook was developed a priori by KER and WGL that included general feedback categories (e.g., feedback on intervention format, intervention materials, module content, and satisfaction with intervention). Interviews were independently coded by at least two team members using this codebook. Consensus meetings were led by KER, and the codebook was iteratively modified as new themes were identified (Charmaz, 2004; Hill et al., 2005). Themes around feedback and suggested changes to EMPOWER were summarized and manual modifications were made incorporating feedback. Additional feedback from key informants on the modifications and revised manual, as well as feedback provided in the exit interviews with open trial participants, followed the same procedures used in the first round. Minor modifications were made, resulting in a finalized EMPOWER intervention manual.

For Part 2, we computed descriptive statistics to characterize the feasibility and acceptability of EMPOWER by examining helpfulness/satisfaction ratings, rates of recruitment, attrition, and number of modules and booster calls completed. Targets were completion of 4 of 6 modules for feasibility and almost all positive feedback for acceptability. To evaluate the 
EMPOWER FOR SURROGATES OF CRITICALLY ILL PATIENTS

preliminary effects of EMPOWER, we used descriptive statistics and Dunlap's d within-subjects effect size estimates (Dunlap et al., 1996) at each longitudinal timepoint relative to baseline.

\section{Results}

\section{Part 1}

We enrolled 5 bereaved surrogates of patients who were uncommunicative and died in the ICU and 10 ICU $(n=7)$ and mental health $(n=3)$ clinicians, including nurses, social workers, psychologists, and a critical care physician, to obtain their feedback on EMPOWER. This number of key informants was selected to ensure sufficiently comprehensive feedback about the manual from multiple perspectives (Morse, 1994). Themes of stakeholder feedback consisted of general feedback on the intervention approach, format and materials, reasons EMPOWER may be helpful to surrogates, elements of each module and booster session that should remain or be modified, and suggested additions to the intervention. Overall, both provider and surrogate stakeholders viewed EMPOWER as having the potential to benefit surrogates, with only one surrogate stakeholder of five noting a preference for standard psychotherapy. Participants also provided feedback more broadly on important considerations for interventionists delivering EMPOWER given the unique needs of surrogates and the ICU setting. Stakeholders described the importance of providing surrogates with psychoeducation about the purpose of EMPOWER and intervention techniques used in the modules. Feedback suggested that interventionists delivering EMPOWER should also be familiar with the myriad challenges of the ICU setting and that it would be important for them to be attentive to the patient's case in order to best partner with the surrogate. They noted the critical need for interventionists to be mindful of the surrogate's receptivity and shifting needs due to the ever-changing nature of the ICU setting. To that end, stakeholders shared either observed or personal experiences of surrogates in the ICU of 
which interventionists should be aware. Elements of these experiences were woven in throughout the manual to further tailor it to this unique population. Despite stakeholders noting some potential challenges of providing an intervention in the ICU, they emphasized the need for such an intervention and the utility of EMPOWER's flexible, modular nature.

Feedback on the EMPOWER format resulted in several changes, including reducing or further defining clinical jargon (e.g., mindfulness, trauma), improving navigability (e.g., table of contents), changing use of binary gender terms to non-binary (e.g., they/them/their), making EMPOWER applicable for a broad range of illness scenarios, and changing the order of several modules. Stakeholders provided suggestions for changes to module format and content, with most feedback centering on the provision of more instructions for interventionists and, similarly, more psychoeducation on intervention techniques for surrogates. Detailed content and formatting changes made in each of the six modules are summarized in Table 2. Finally, participants suggested minor modifications to the handouts included in the EMPOWER manual to clarify exercise instructions and increase their relevance.

Round 2 feedback and exit interviews included positive feedback on the manual, with only minor additional changes suggested. These included slight changes to handout language for clarity and several recommendations for interventionists similar to those provided in the first round (e.g., interventionist should be attentive to medical circumstances of the patient and shifting surrogate needs and emotions).

\section{Part 2}

\section{Participant Characteristics}

Details about the 10 surrogates who participated in the open trial are presented in Table 3. The majority of participants were under age 65, White, non-Hispanic, high school graduates, and 
EMPOWER FOR SURROGATES OF CRITICALLY ILL PATIENTS

adult children of the patients. Data for 9 of the patients whom the surrogates were caring for were available. Four of the 9 had active cancer (split evenly between liquid and solid tumor cancers). Two patients died between the T1 and T2 assessments. Three patients died between the T2 assessment and the T3 assessment one month post-baseline. One patient died between the T3 assessment and the T4 assessment three months post-baseline, leaving a remaining four patients who survived the study period.

\section{Feasibility and Acceptability}

Recruitment was challenging, as expected with this population. We received consent to approach 87 patient-surrogate dyads. For 23 of these dyads (26\%), the patient died, was discharged, or regained decision-making capacity before the surrogate could be approached. Of the 64 surrogates who were approached, 49 (77\%) declined participation. Reasons for refusal included reporting a sufficient level of support, feeling too busy to participate and concerns about the time commitment involved in participating, and not wanting to leave the patient's bedside. Fifteen participants (23\%) completed the screening process. Of these, one participant did not meet eligibility criteria, and four dropped out before receiving the intervention due to scheduling challenges and/or declining patient status. This yielded a total of 10 participants who completed the baseline assessment and received the EMPOWER intervention. Two surrogate decision-makers withdrew from the study. One surrogate withdrew while completing the T2 assessment, as the indexed patient had died a week prior and they no longer wished to participate. Thus, post-intervention, follow-up, and patient data for this participant are missing for this participant. The other was an international participant who was lost to follow-up when they returned to their home country during the study period. In all, six participants completed the T3 assessment, and eight completed the T4 assessment. Surrogates were enrolled a median 22 
days after the patient's ICU admission (minimum 3 days, maximum 38 days).

Overall, EMPOWER appeared feasible, with $100 \%$ of participants who began the intervention completing all 6 modules. Completion of the booster calls was less consistent. Of the nine participants eligible for a booster call (excluding the participant who dropped during administration of T2), five completed both booster calls. The remaining four participants did not complete any booster calls.

Acceptability of the EMPOWER intervention appeared strong, with post-intervention ratings of effectiveness and helpfulness both averaging an 8 out of 10. See Table 4 for additional post-intervention ratings from the PISQ. Exit interviews provided more evidence of acceptability. In responding to a question about whether EMPOWER was helpful, a 31-year-old surrogate caring for her mother with metastatic non-small cell lung cancer stated, "And, you know, when everything was said and done-because my mother did pass the day after-I think it was a huge, huge help." Another, a 51-year-old surrogate caring for her husband with acute myeloid leukemia commented about the intervention, "I thought it was fabulous." When asked whether what was discussed in EMPOWER was actually applicable to what was going on in the ICU setting, she responded, "Yeah, because I think I used that - - used that and it opened my eyes. Yeah, I definitely do.” In response to a question about whether the intervention was helpful, a 67-year-old caring for her husband with myelodysplastic syndrome replied, "Well I think that it's very helpful. I think it should continue." When a separate surrogate was asked what helped most, the 57-year-old caring for her Mother with chronic obstructive pulmonary disease expressed, "And actually was a professional who I felt safe - I felt like, you know, not only did somebody have my back, there's a lot of people who give you advice and support but this is someone that knew what she was talking about." 
EMPOWER FOR SURROGATES OF CRITICALLY ILL PATIENTS

\section{Exploration of Preliminary Efficacy}

Table 5 shows pooled descriptive statistics and effect size estimates for outcomes of interest. Examining acute effects immediately after the 6-module, 1.5- to 2-hour intervention, a small within-subjects effect at T2 was observed for the primary outcome, peritraumatic distress (Dunlap's d $\geq 0.2$ ). A large within-subjects effect at T2 was observed for anxiety as measured by the HADS Anxiety Subscale among the two participants who received it (Dunlap's d $\geq 0.8$ ), and a small to moderate effect was observed for anxiety as measured by the GAD-7 (Dunlap's 0.2 > $\mathrm{d}<0.5$ ). There was also a small effect at T2 on experiential avoidance (Dunlap's $d \geq 0.2$ ).

One month post-baseline (T3), a moderate within-subjects effect was observed for depression (Dunlap's $0.5 \leq \mathrm{d}<0.8$ ); a small to moderate effect was observed for prolonged grief symptoms (Dunlap's $0.2 \leq \mathrm{d}<0.5$ ); and small effects were observed for anxiety, experiential avoidance, and posttraumatic stress symptoms (Dunlap's $d \geq 0.2$ ). At three months post-baseline (T4), we found a large effect on prolonged grief symptoms (Dunlap's d > 0.8) and small intervention effects for depression, anxiety, and experiential avoidance (Dunlap's $d \geq 0.2$ ).

Patient outcomes were also examined. We found that DNR orders were placed for 4 out of the 9 patients with available data during their indexed ICU stay. For two of these patients, these orders were placed before study enrollment. For the other 2 patients, these orders were placed 25 and 27 days, respectively, after receiving the EMPOWER intervention. All 9 patients were receiving mechanical ventilation. Extubation occurred in four patients. Withdrawal of lifesustaining care did not occur in any of the patients.

\section{Discussion}

The overall goal of this study was to develop, refine, and pilot test of a brief manualized psychological intervention, EMPOWER, to determine its preliminary feasibility, acceptability, 
and promise in improving surrogates' mental health symptoms and patient outcomes.

EMPOWER was designed to be adaptable to the fast-paced, often chaotic, ICU milieu, using ultra-brief, evidence-based interventions (Sperry \& Binensztok, 2019) to reduce peritraumatic stress, grief, anxiety, and experiential avoidance. EMPOWER targets surrogates who are anxious and/or closely attached to the patient because these individuals are at greatest risk for developing poor outcomes, such as PTSD and PGD, following the patient's death or discharge from the ICU (Andrews et al., 2009; Bryant et al., 2008; Gartlehner et al., 2013; Prigerson et al., 2009). Importantly, unlike many interventions developed for grief and trauma, EMPOWER was developed by incorporating both provider and surrogate feedback, improving its acceptability and utility for the uniquely challenging circumstances of the ICU. In Part 1 of the study, we used participant feedback to improve the comprehensibility of EMPOWER's psychoeducation and exercises by minimizing the use of jargon and reorganizing the order of the content so that it would be more digestible.

We found that recruitment for the Part 2 open trial of EMPOWER was feasible, although there were challenges to enrolling surrogates, with only $23 \%$ of those approached consenting. This is understandable given that EMPOWER approaches family surrogates in, perhaps, one of the most stressful times of their lives. We observed that some surrogates expressed interest in the EMPOWER intervention but did not want to complete the assessments and therefore did not consent to the study. Completion of the intervention itself appeared to be highly feasible, with $100 \%$ of participants completing all six of the brief modules, exceeding our target. However, only 5 of the 9 participants still participating after T2 completed booster calls. There are many explanations for this, including caregiving demands, patients' health fluctuations, and coping with acute grief when the patient had died. Completion of the second booster call among all those who 
were able to complete the first suggests participants may have found the calls helpful. The intervention itself appeared highly acceptable, with surrogates providing high ratings of effectiveness and helpfulness as well as generally positive feedback in the exit interviews.

On average, reductions in psychological symptoms were observed among our small sample of surrogates on key outcomes. Surrogates are often weighed down by anxiety and anticipatory grief over the impending death of the patient while faced with making life-and-death decisions on the patient's behalf in the potentially traumatic conditions of the ICU. The fact that after just 1.5 to 2 hours of intervention over approximately 1 week, participants reported decreases in acute symptoms, including peritraumatic stress, anxiety, and experiential avoidance, has important implications. Such symptom improvements may not only translate into reducing suffering for surrogates themselves, but they may also help surrogates better engage in and process critical communication with the patient's ICU care team.

Over time, the impact of applying the coping tools taught through EMPOWER appeared to have been beneficial, as we observed reductions in symptoms of experiential avoidance, prolonged grief, depression, anxiety, and posttraumatic stress symptoms one month after the intervention. At three months post-baseline, the effect on prolonged grief symptoms increased and gains appeared maintained for depression, anxiety, and experiential avoidance. For the most part, observed effects were small to moderate. However, given the limited amount of time EMPOWER takes to administer and the fact that $60 \%$ of participants also became bereaved during the study time period, these preliminary findings are encouraging.

While the small sample size in the present study precluded mediation analyses, our findings that experiential avoidance decreased in parallel with reductions in other psychological outcomes suggest that it may serve as a mechanism of change. By reducing experiential 
avoidance, surrogates' ability to tolerate distress and be emotionally activated (FernandezRodriguez et al., 2018) during the ICU stay may increase. This in turn may help them to digest medical information they are given, make decisions that are aligned with their and the patient's values, and allow them to be more present with and emotionally available for the patient, whose time may be limited. Thus, reducing experiential avoidance may assist with improving end-oflife decision-making on behalf of the patient and minimize regrets (Hickman et al., 2012). Furthermore, given that experiential avoidance is an important predictor of psychiatric disorders, including depression, anxiety, prolonged grief, and PTSD (Marx \& Sloan, 2005b; SerranoIbanez et al., 2021; Spinhoven et al., 2016; Spinhoven et al., 2017; Williams et al., 2019), reducing such avoidance may have longer-term psychological benefits.

It should be noted that the goal of EMPOWER is not to eliminate grief, anxiety and traumatic stress reactions, but rather to help surrogates to respond to these reactions adaptively (e.g., minimizing experiential avoidance) and compassionately, helping to reduce numbing by titrating exposure to difficult feelings whenever possible. It additionally provides a space to do their "due diligence" in reflecting on their and the patient's values and circumstances so that they may feel empowered in the decision-making process (Tunzi, 2012).

\section{Study Limitations and Future Directions}

This proof-of-concept evaluation has several limitations, including the small sample size, homogeneity with respect to race and ethnicity, and the use of a within-subjects design. The absence of a comparison group, though typical of early pilot work, limits conclusions that can be drawn about observed improvements of symptoms, which may have decreased naturally over time. Further complicating our ability to draw conclusions is the fact that several participants became bereaved, and at varying time points, during the study period; this is a challenge inherent 
EMPOWER FOR SURROGATES OF CRITICALLY ILL PATIENTS

to this type of research but is an important consideration in interpreting the findings. Another weakness of the study was the use of self-report assessments, which can be influenced by differing interpretations of questions and response scales. As we received feedback from participants about unclear assessment items, we removed items and/or selected new measures in preparation for a pilot randomized controlled trial. We thus have partial data in several instances, and our findings should be considered with this limitation in mind.

The next step in developing EMPOWER is conducting a Stage IB feasibility randomized controlled trial to prepare for a larger-scale efficacy trial (Rounsaville et al., 2001). We will focus on strengthening recruitment strategies and supporting completion of booster calls, or eliminating them if we find that they are not wanted or impactful. We also plan on exploring the mediating role of experiential avoidance, including any distinctions between the effects of global versus momentary experiential avoidance (Levin et al., 2018), in future trials. Although we did not find evidence of EMPOWER impacting patient outcomes, including consenting to DNR orders or withdrawal of life support, in the present trial, given our single-arm design, small sample size, and the diversity of patient circumstances we observed, we will continue to investigate whether the intervention impacts patient care. Identification of facilitators and barriers to future dissemination and implementation of EMPOWER should also be a focus, including how the intervention may integrate into bereavement services (McAdam \& Erikson, 2016). Although obstacles to the delivery of an effective mental health intervention in the ICU loom large, the need for such an intervention could not be greater. Our observation of its preliminary feasibility, acceptability, and promise in reducing a range of psychological symptoms suggest further evaluation is warranted.

\section{Conflicts of Interest}


EMPOWER FOR SURROGATES OF CRITICALLY ILL PATIENTS

None

\section{Funding Statement}

This research was supported by National Cancer Institute (NCI) grant R21CA218313

(Prigerson/Lichtenthal) and American Cancer Society grant 130534-PEP-17-053-01-PCSM.

Research efforts were additionally supported by NCI grants R35CA197730 (Prigerson),

K07CA172216 (Lichtenthal), P30CA008748 (Thompson), and T32CA009461 (Ostroff).

\section{References}

Anderson, W. G., Arnold, R. M., Angus, D. C., \& Bryce, C. L. (2008). Posttraumatic stress and complicated grief in family members of patients in the intensive care unit. J Gen Intern Med, 23(11), 1871-1876. https://doi.org/10.1007/s11606-008-0770-2

Andrews, B., Brewin, C. R., Stewart, L., Philpott, R., \& Hejdenberg, J. (2009). Comparison of immediate-onset and delayed-onset posttraumatic stress disorder in military veterans. $J$ Abnorm Psychol, 118(4), 767-777. https://doi.org/10.1037/a0017203

Azoulay, E., Pochard, F., Kentish-Barnes, N., Chevret, S., Aboab, J., Adrie, C., Annane, D., Bleichner, G., Bollaert, P. E., Darmon, M., Fassier, T., Galliot, R., Garrouste-Orgeas, M., Goulenok, C., Goldgran-Toledano, D., Hayon, J., Jourdain, M., Kaidomar, M., Laplace, C., Larche, J., Liotier, J., Papazian, L., Poisson, C., Reignier, J., Saidi, F., \& Schlemmer, B. (2005). Risk of post-traumatic stress symptoms in family members of intensive care unit patients. Am J Respir Crit Care Med, 171(9), 987-994.

https://doi.org/10.1164/rccm.200409-12950C

Birur, B., Moore, N. C., \& Davis, L. L. (2016). An Evidence-Based Review of Early Intervention and Prevention of Posttraumatic Stress Disorder. Community Ment Health J. https://doi.org/10.1007/s10597-016-0047-X 
Bishop, L. S., Ameral, V. E., \& Palm Reed, K. M. (2018). The Impact of Experiential Avoidance and Event Centrality in Trauma-Related Rumination and Posttraumatic Stress. Behav Modif, 42(6), 815-837. https://doi.org/10.1177/0145445517747287

Boelen, P. A., de Keijser, J., van den Hout, M. A., \& van den Bout, J. (2007). Treatment of complicated grief: a comparison between cognitive-behavioral therapy and supportive counseling. J Consult Clin Psychol, 75(2), 277-284. https://doi.org/10.1037/0022$\underline{006 X .75 .2 .277}$

Briere, J., \& Lanktree, C. B. (2013). Integrative treatment of complex trauma for adolescents (ITCT-A): A guide for the treatment of multiply-traumatized youth, 2nd edition. USC Adolescent Trauma Treatment Training Center, National Child Traumatic Stress Network, U.S. Department of Substance Abuse and Mental Health Services Administration.

Brunet, A., Weiss, D. S., Metzler, T. J., Best, S. R., Neylan, T. C., Rogers, C., Fagan, J., \& Marmar, C. R. (2001). The Peritraumatic Distress Inventory: a proposed measure of PTSD criterion A2. Am J Psychiatry, 158(9), 1480-1485. https://doi.org/10.1176/appi.ajp.158.9.1480

Bryant, R. A., Kenny, L., Joscelyne, A., Rawson, N., Maccallum, F., Cahill, C., Hopwood, S., Aderka, I., \& Nickerson, A. (2014). Treating prolonged grief disorder: a randomized clinical trial. JAMA Psychiatry, 71(12), 1332-1339. https://doi.org/10.1001/jamapsychiatry.2014.1600

Bryant, R. A., Mastrodomenico, J., Felmingham, K. L., Hopwood, S., Kenny, L., Kandris, E., Cahill, C., \& Creamer, M. (2008). Treatment of acute stress disorder: a randomized 
controlled trial. Arch Gen Psychiatry, 65(6), 659-667. https://doi.org/10.1001/archpsyc.65.6.659

Bryant, R. A., Moulds, M. L., \& Nixon, R. V. (2003). Cognitive behaviour therapy of acute stress disorder: a four-year follow-up. Behav Res Ther, 41(4), 489-494.

Bunnell, B. E., Davidson, T. M., \& Ruggiero, K. J. (2018). The Peritraumatic Distress Inventory: Factor structure and predictive validity in traumatically injured patients admitted through a Level I trauma center. J Anxiety Disord, 55, 8-13. https://doi.org/10.1016/j.janxdis.2018.03.002

Carson, S. S., Cox, C. E., Wallenstein, S., Hanson, L. C., Danis, M., Tulsky, J. A., Chai, E., \& Nelson, J. E. (2016). Effect of Palliative Care-Led Meetings for Families of Patients With Chronic Critical Illness: A Randomized Clinical Trial. Jama, 316(1), 51-62. https://doi.org/10.1001/jama.2016.8474

Charmaz, K. (2004). Premises, principles, and practices in qualitative research: revisiting the foundations. Qual Health Res, 14(7), 976-993. https://doi.org/10.1177/1049732304266795

Cohen, S. R., Mount, B. M., Strobel, M. G., \& Bui, F. (1995). The McGill Quality of Life Questionnaire: a measure of quality of life appropriate for people with advanced disease. A preliminary study of validity and acceptability. Palliat Med, 9(3), 207-219. https://doi.org/10.1177/026921639500900306

Cox, C. E., White, D. B., Hough, C. L., Jones, D. M., Kahn, J. M., Olsen, M. K., Lewis, C. L., Hanson, L. C., \& Carson, S. S. (2019). Effects of a Personalized Web-Based Decision Aid for Surrogate Decision Makers of Patients With Prolonged Mechanical Ventilation: A Randomized Clinical Trial. Ann Intern Med. https://doi.org/10.7326/M18-2335 
Cox, C. E., Wysham, N. G., Walton, B., Jones, D., Cass, B., Tobin, M., Jonsson, M., Kahn, J. M., White, D. B., Hough, C. L., Lewis, C. L., \& Carson, S. S. (2015). Development and usability testing of a Web-based decision aid for families of patients receiving prolonged mechanical ventilation. Ann Intensive Care, 5, 6. https://doi.org/10.1186/s13613-015$\underline{0045-0}$

Curtis, J. R., Back, A. L., Ford, D. W., Downey, L., Shannon, S. E., Doorenbos, A. Z., Kross, E. K., Reinke, L. F., Feemster, L. C., Edlund, B., Arnold, R. W., O'Connor, K., \& Engelberg, R. A. (2013). Effect of communication skills training for residents and nurse practitioners on quality of communication with patients with serious illness: a randomized trial. Jama, 310(21), 2271-2281. https://doi.org/10.1001/jama.2013.282081

de Meyrick, J. (2003). The Delphi method and health research [Journal; Peer Reviewed Journal]. Health Education, .103(1), pp. https://doi.org/http://dx.doi.org/10.1108/09654280310459112

Derry, H. M., Lief, L., Schenck, E. J., Berlin, D. A., \& Prigerson, H. G. (2020). Peritraumatic Stress among Caregivers of Patients in the Intensive Care Unit. Ann Am Thorac Soc, 17(5), 650-654. https://doi.org/10.1513/AnnalsATS.201908-647RL

Dionne-Odom, J. N., Ejem, D. B., Wells, R., Azuero, A., Stockdill, M. L., Keebler, K., Sockwell, E., Tims, S., Engler, S., Kvale, E., Durant, R. W., Tucker, R. O., Burgio, K. L., Tallaj, J., Pamboukian, S. V., Swetz, K. M., \& Bakitas, M. A. (2020). Effects of a Telehealth Early Palliative Care Intervention for Family Caregivers of Persons With Advanced Heart Failure: The ENABLE CHF-PC Randomized Clinical Trial. JAMA Netw Open, 3(4), e202583. https://doi.org/10.1001/jamanetworkopen.2020.2583 
Dunlap, W. P., Cortina, J. M., Vaslow, J. B., \& Burke, M. J. (1996). Meta-analysis of experiments with matched groups or repeated measures designs [Peer Reviewed]. Psychological Methods, .1(2), pp. https://doi.org/10.1037/1082-989X.1.2.170

Fernandez-Rodriguez, C., Paz-Caballero, D., Gonzalez-Fernandez, S., \& Perez-Alvarez, M. (2018). Activation vs. Experiential Avoidance as a Transdiagnostic Condition of Emotional Distress: An Empirical Study. Front Psychol, 9, 1618. https://doi.org/10.3389/fpsyg.2018.01618

Foa, E. B., Hembree, E. A., \& Rothbaum, B. O. (2007). Prolonged exposure therapy for PTSD : emotional processing of traumatic experiences : therapist guide. Oxford University Press. Table of contents only http://www.loc.gov/catdir/toc/ecip072/2006032823.html Publisher description http://www.loc.gov/catdir/enhancements/fy0725/2006032823-d.html

Gamez, W., Chmielewski, M., Kotov, R., Ruggero, C., Suzuki, N., \& Watson, D. (2014). The brief experiential avoidance questionnaire: development and initial validation. Psychol Assess, 26(1), 35-45. https://doi.org/10.1037/a0034473

Gamez, W., Chmielewski, M., Kotov, R., Ruggero, C., \& Watson, D. (2011). Development of a measure of experiential avoidance: the Multidimensional Experiential Avoidance Questionnaire. Psychol Assess, 23(3), 692-713. https://doi.org/10.1037/a0023242

Garrido, M. M., \& Prigerson, H. G. (2014). The end-of-life experience: modifiable predictors of caregivers' bereavement adjustment. Cancer, 120(6), 918-925. https://doi.org/10.1002/cncr.28495

Gartlehner, G., Forneris, C. A., Brownley, K. A., Gaynes, B. N., Sonis, J., Coker-Schwimmer, E., Jonas, D. E., Greenblatt, A., Wilkins, T. M., Woodell, C. L., \& Lohr, K. N. (2013). AHRQ Comparative Effectiveness Reviews. In Interventions for the Prevention of 
EMPOWER FOR SURROGATES OF CRITICALLY ILL PATIENTS

\section{Posttraumatic Stress Disorder (PTSD) in Adults After Exposure to Psychological}

Trauma. Agency for Healthcare Research and Quality (US).

Glick, D. R., Motta, M., Wiegand, D. L., Range, P., Reed, R. M., Verceles, A. C., Shah, N. G., \& Netzer, G. (2018). Anticipatory grief and impaired problem solving among surrogate decision makers of critically ill patients: A cross-sectional study. Intensive Crit Care Nurs, 49, 1-5. https://doi.org/10.1016/j.iccn.2018.07.006

Gough, K., \& Hudson, P. (2009). Psychometric properties of the Hospital Anxiety and Depression Scale in family caregivers of palliative care patients. J Pain Symptom Manage, 37(5), 797-806. https://doi.org/10.1016/j.jpainsymman.2008.04.012

Greenberg, J. A., Basapur, S., Quinn, T. V., Bulger, J. L., Glover, C. M., \& Shah, R. C. (2021). Psychological Symptoms Among Surrogates of Critically Ill Patients During and Before the COVID-19 Pandemic. Chest. https://doi.org/10.1016/j.chest.2020.12.056

Haydar, S. A., Strout, T. D., Bond, A. G., \& Han, P. K. (2019). Prognostic value of a modified surprise question designed for use in the emergency department setting. Clin Exp Emerg Med, 6(1), 70-76. https://doi.org/10.15441/ceem.17.293

Hickman, R. L., Jr., Daly, B. J., \& Lee, E. (2012). Decisional conflict and regret: consequences of surrogate decision making for the chronically critically ill. Appl Nurs Res, 25(4), 271275. https://doi.org/10.1016/j.apnr.2011.03.003

Higgins, P. C., Garrido, M. M., \& Prigerson, H. G. (2015). Factors Predicting Bereaved Caregiver Perception of Quality of Care in the Final Week of Life: Implications for Health Care Providers. J Palliat Med, 18(10), 849-857. https://doi.org/10.1089/jpm.2015.29001.hp 
Hill, C. E., Knox, S., Thompson, B. J., Williams, E. N., Hess, S. A., \& Ladany, N. (2005). Consensual Qualitative Research: An Update [Journal; Peer Reviewed Journal]. Journal of Counseling Psychology, 52(2), 196-205.

Johnson, J. G., Vanderwerker, L. C., Bornstein, R. F., \& Prigerson, H. G. (2006). Development and Validation of an Instrument for the Assessment of Dependency Among Bereaved Persons. Journal of Psychopathology and Behavioral Assessment, 28(4), 26-641.

Johnson, J. G., Zhang, B., Greer, J. A., \& Prigerson, H. G. (2007). Parental control, partner dependency, and complicated grief among widowed adults in the community. $J$ Nerv Ment Dis, 195(1), 26-30. https://doi.org/10.1097/01.nmd.0000252009.45915.b2

Kelly, M. M., Sido, H., Forsyth, J. P., Ziedonis, D. M., Kalman, D., \& Cooney, J. L. (2015). Acceptance and commitment therapy smoking cessation treatment for veterans with posttraumatic stress disorder: a pilot study. J Dual Diagn, 11(1), 50-55. https://doi.org/10.1080/15504263.2014.992201

Kentish-Barnes, N., Chaize, M., Seegers, V., Legriel, S., Cariou, A., Jaber, S., Lefrant, J. Y., Floccard, B., Renault, A., Vinatier, I., Mathonnet, A., Reuter, D., Guisset, O., CohenSolal, Z., Cracco, C., Seguin, A., Durand-Gasselin, J., Eon, B., Thirion, M., Rigaud, J. P., Philippon-Jouve, B., Argaud, L., Chouquer, R., Adda, M., Dedrie, C., Georges, H., Lebas, E., Rolin, N., Bollaert, P. E., Lecuyer, L., Viquesnel, G., Leone, M., ChalumeauLemoine, L., Garrouste, M., Schlemmer, B., Chevret, S., Falissard, B., \& Azoulay, E. (2015). Complicated grief after death of a relative in the intensive care unit. Eur Respir J, 45(5), 1341-1352. https://doi.org/10.1183/09031936.00160014 
EMPOWER FOR SURROGATES OF CRITICALLY ILL PATIENTS

Kroenke, K., Spitzer, R. L., \& Williams, J. B. (2001). The PHQ-9: validity of a brief depression severity measure. J Gen Intern Med, 16(9), 606-613. https://doi.org/10.1046/j.15251497.2001.016009606.x

Lautrette, A., Darmon, M., Megarbane, B., Joly, L. M., Chevret, S., Adrie, C., Barnoud, D., Bleichner, G., Bruel, C., Choukroun, G., Curtis, J. R., Fieux, F., Galliot, R., GarrousteOrgeas, M., Georges, H., Goldgran-Toledano, D., Jourdain, M., Loubert, G., Reignier, J., Saidi, F., Souweine, B., Vincent, F., Barnes, N. K., Pochard, F., Schlemmer, B., \& Azoulay, E. (2007). A communication strategy and brochure for relatives of patients dying in the ICU. N Engl J Med, 356(5), 469-478. https://doi.org/10.1056/NEJMoa063446

Levin, M. E., Krafft, J., Pierce, B., \& Potts, S. (2018). When is experiential avoidance harmful in the moment? Examining global experiential avoidance as a moderator. J Behav Ther Exp Psychiatry, 61, 158-163. https://doi.org/10.1016/j.jbtep.2018.07.005

Litz, B. T., Schorr, Y., Delaney, E., Au, T., Papa, A., Fox, A. B., Morris, S., Nickerson, A., Block, S., \& Prigerson, H. G. (2014). A randomized controlled trial of an internet-based therapist-assisted indicated preventive intervention for prolonged grief disorder. Behav Res Ther, 61, 23-34. https://doi.org/10.1016/j.brat.2014.07.005

Lovell, G. P., Smith, T., \& Kannis-Dymand, L. (2015). Surrogate End-of-Life Care Decision Makers' Postbereavement Grief and Guilt Responses. Death Stud, 39(10), 647-653. https://doi.org/10.1080/07481187.2015.1047062

Mack, J. W., Weeks, J. C., Wright, A. A., Block, S. D., \& Prigerson, H. G. (2010). End-of-life discussions, goal attainment, and distress at the end of life: predictors and outcomes of 
EMPOWER FOR SURROGATES OF CRITICALLY ILL PATIENTS

receipt of care consistent with preferences. J Clin Oncol, 28(7), 1203-1208. https://doi.org/10.1200/JCO.2009.25.4672

Marx, B. P., \& Sloan, D. M. (2005a). Peritraumatic dissociation and experiential avoidance as predictors of posttraumatic stress symptomatology. Behav Res Ther, 43(5), 569-583. https://doi.org/10.1016/j.brat.2004.04.004

Marx, B. P., \& Sloan, D. M. (2005b). Peritraumatic dissociation and experiential avoidance as predictors of posttraumatic stress symptomatology. Behaviour Research and Therapy, 43(5), 569-583. https://doi.org/10.1016/j.brat.2004.04.004

McAdam, J. L., \& Erikson, A. (2016). Bereavement Services Offered in Adult Intensive Care Units in the United States. American Journal of Critical Care, 25(2), 110-117. https://doi.org/10.4037/ajcc2016981

McLean, C., \& Follette, V. M. (2016). Acceptance and commitment therapy as a nonpathologizing intervention approach for survivors of trauma. J Trauma Dissociation, 17(2), 138-150. https://doi.org/10.1080/15299732.2016.1103111

Mitchell, J. T., \& Everly, G. S., Jr. (1995). The critical incident stress debriefing (CISD) and the prevention of work-related traumatic stress among high risk occupational groups. In G. S. Everly, Jr. \& J. M. Lating (Eds.), Plenum series on stress and coping. Psychotraumatology: Key papers and core concepts in post-traumatic stress (pp. 267280). Plenum Press.

Morse, J. M. (1994). Designing funded qualitative research. In N. K. Denzin \& Y. S. Lincoln (Eds.), Handbook of qualitative research (pp. 220-235). Sage Publications, Inc.

Neimeyer, R. A. (2012). Techniques of grief therapy : creative practices for counseling the bereaved. Routledge. 
Neimeyer, R. A. (2016). Techniques of grief therapy : assessment and intervention. Routledge, Taylor \& Francis Group.

Nolan, M. T., Hughes, M. T., Kub, J., Terry, P. B., Astrow, A., Thompson, R. E., Clawson, L., Texeira, K., \& Sulmasy, D. P. (2009). Development and validation of the Family Decision-Making Self-Efficacy Scale. Palliat Support Care, 7(3), 315-321. https://doi.org/10.1017/s1478951509990241

Orsillo, S. M., \& Batten, S. V. (2005). Acceptance and commitment therapy in the treatment of posttraumatic stress disorder. Behav Modif, 29(1), 95-129. https://doi.org/10.1177/0145445504270876

Plumb, J. C., Orsillo, S. M., \& Luterek, J. A. (2004). A preliminary test of the role of experiential avoidance in post-event functioning. J Behav Ther Exp Psychiatry, 35(3), 245-257. https://doi.org/10.1016/j.jbtep.2004.04.011

Prigerson, H. G., Horowitz, M. J., Jacobs, S. C., Parkes, C. M., Aslan, M., Goodkin, K., Raphael, B., Marwit, S. J., Wortman, C., Neimeyer, R. A., Bonanno, G. A., Block, S. D., Kissane, D., Boelen, P., Maercker, A., Litz, B. T., Johnson, J. G., First, M. B., \& Maciejewski, P. K. (2009). Prolonged grief disorder: Psychometric validation of criteria proposed for DSM-V and ICD-11. PLoS Med, 6(8), e1000121. https://doi.org/10.1371/journal.pmed.1000121

Prigerson, H. G., Vanderwerker, L. C., \& Maciejewski, P. K. (Eds.). (2008). A Case for the Inclusion of Prolonged Grief Disorder in DSM-V. American Psychological Association Press.

Prigerson, H. G., Viola, M., Brewin, C. R., Cox, C., Ouyang, D., Rogers, M., Pan, C. X., Rabin, S., Xu, J., Vaughan, S., Gordon-Elliot, J. S., Berlin, D., Lief, L., \& Lichtenthal, W. G. 
EMPOWER FOR SURROGATES OF CRITICALLY ILL PATIENTS

(2019). Enhancing \& Mobilizing the POtential for Wellness \& Emotional Resilience (EMPOWER) among Surrogate Decision-Makers of ICU Patients: study protocol for a randomized controlled trial. Trials, 20(1), 408. https://doi.org/10.1186/s13063-019-3515$\underline{0}$

Rodriguez Villar, S., Sanchez Casado, M., Prigerson, H. G., Mesa Garcia, S., Rodriguez Villar, M., Hortiguela Martin, V. A., Marco Schulke, C. M., Barrientos Vega, R., \& Quintana, M. (2012). Prolonged grief disorder in the next of kin of adult patients who die during or after admission to intensive care. Chest, 141(6), 1635-1636.

Rounsaville, B. J., Carroll, K. M., \& Onken, L. S. (2001). A stage model of behavioral therapies research: Getting started and moving on from Stage I. Clinical Psychology: Science and Practice, 8, 133-142.

Schenker, Y., Crowley-Matoka, M., Dohan, D., Tiver, G. A., Arnold, R. M., \& White, D. B. (2012). I don't want to be the one saying 'we should just let him die': intrapersonal tensions experienced by surrogate decision makers in the ICU. J Gen Intern Med, 27(12), 1657-1665. https://doi.org/10.1007/s11606-012-2129-y

Serrano-Ibanez, E. R., Ruiz-Parraga, G. T., Gomez-Perez, L., Ramirez-Maestre, C., Esteve, R., \& Lopez-Martinez, A. E. (2021). The Relationship Between Experiential Avoidance and Posttraumatic Stress Symptoms: A Moderated Mediation Model Involving Dissociation, Guilt, and Gender. J Trauma Dissociation, 1-15. https://doi.org/10.1080/15299732.2020.1869647

Siegel, M. D., Hayes, E., Vanderwerker, L. C., Loseth, D. B., \& Prigerson, H. G. (2008). Psychiatric illness in the next of kin of patients who die in the intensive care unit. Crit Care Med, 36(6), 1722-1728. https://doi.org/10.1097/CCM.0b013e318174da72 
Simons, J. S., \& Gaher, R. M. (2005). The distress tolerance scale: development and validation of a self-report measure. Motivation and Emotion, 29, 83-102.

Sperry, L., \& Binensztok, V. (2019). Ultra-brief cognitive behavioral interventions : a new practice model for mental health and integrated care. Routledge.

Spinhoven, P., Drost, J., de Rooij, M., van Hemert, A. M., \& Penninx, B. W. (2016). Is Experiential Avoidance a Mediating, Moderating, Independent, Overlapping, or Proxy Risk Factor in the Onset, Relapse and Maintenance of Depressive Disorders? Cognit Ther Res, 40, 150-163. https://doi.org/10.1007/s10608-015-9747-8

Spinhoven, P., van Hemert, A. M., \& Penninx, B. (2017). Experiential Avoidance and Bordering Psychological Constructs as Predictors of the Onset, Relapse and Maintenance of Anxiety Disorders: One or Many? Cognit Ther Res, 41(6), 867-880. https://doi.org/10.1007/s10608-017-9856-7

Spitzer, R. L., Kroenke, K., Williams, J. B., \& Lowe, B. (2006). A brief measure for assessing generalized anxiety disorder: the GAD-7. Arch Intern Med, 166(10), 1092-1097. https://doi.org/10.1001/archinte.166.10.1092

Tunzi, M. (2012). A new standard for incapacitated patient decision making: the clinical standard of surrogate empowerment. J Clin Ethics, 23(4), 316-330. https://www.ncbi.nlm.nih.gov/pubmed/23469692

Walser, R. D., \& Westrup, D. (2007). Acceptance \& commitment therapy for the treatment of post-traumatic stress disorder \& trauma-related problems : a practitioner's guide to using mindfulness \& acceptance strategies. New Harbinger Publications. Table of contents only http://www.loc.gov/catdir/toc/ecip077/2006102707.html 
Weiss, D. S., \& Marmar, C. R. (1996). The Impact of Event Scale - Revised. In J. Wilson \& T. M. Keane (Eds.), Assessing psychological trauma and PTSD (pp. 399-411). Guildford.

White, D. B., Angus, D. C., Shields, A. M., Buddadhumaruk, P., Pidro, C., Paner, C., Chaitin, E., Chang, C. H., Pike, F., Weissfeld, L., Kahn, J. M., Darby, J. M., Kowinsky, A., Martin, S., Arnold, R. M., \& Investigators, P. (2018). A Randomized Trial of a Family-Support Intervention in Intensive Care Units. N Engl J Med, 378(25), 2365-2375. https://doi.org/10.1056/NEJMoa1802637

White, D. B., Cua, S. M., Walk, R., Pollice, L., Weissfeld, L., Hong, S., Landefeld, C. S., \& Arnold, R. M. (2012). Nurse-led intervention to improve surrogate decision making for patients with advanced critical illness. Am J Crit Care, 21(6), 396-409. https://doi.org/10.4037/ajcc2012223

Williams, J. L., Hardt, M. M., Henschel, A. V., \& Eddinger, J. R. (2019). Experiential avoidance moderates the association between motivational sensitivity and prolonged grief but not posttraumatic stress symptoms. Psychiatry Res, 273, 336-342. https://doi.org/10.1016/j.psychres.2019.01.020

Wright, A. A., Keating, N. L., Balboni, T. A., Matulonis, U. A., Block, S. D., \& Prigerson, H. G. (2010). Place of death: correlations with quality of life of patients with cancer and predictors of bereaved caregivers' mental health. J Clin Oncol, 28(29), 4457-4464. https://doi.org/10.1200/JCO.2009.26.3863

Wright, A. A., Zhang, B., Ray, A., Mack, J. W., Trice, E., Balboni, T., Mitchell, S. L., Jackson, V. A., Block, S. D., Maciejewski, P. K., \& Prigerson, H. G. (2008). Associations between end-of-life discussions, patient mental health, medical care near death, and caregiver 
bereavement adjustment. Jama, 300(14), 1665-1673.

https://doi.org/10.1001/jama.300.14.1665

Zhang, B., El-Jawahri, A., \& Prigerson, H. G. (2006). Update on bereavement research: evidence-based guidelines for the diagnosis and treatment of complicated bereavement. $J$ Palliat Med, 9(5), 1188-1203. https://doi.org/10.1089/jpm.2006.9.1188

Zigmond, A. S., \& Snaith, R. P. (1983). The hospital anxiety and depression scale. Acta Psychiatr Scand, 67(6), 361-370. https://doi.org/10.1111/j.1600-0447.1983.tb09716.x 
EMPOWER FOR SURROGATES OF CRITICALLY ILL PATIENTS

Table 1. EMPOWER Overview of Modules

\begin{tabular}{|c|c|c|c|}
\hline \multicolumn{4}{|c|}{ EMPOWER } \\
\hline \multirow{6}{*}{$\begin{array}{l}\text { In } \\
\text { ICU }\end{array}$} & \multirow{6}{*}{$\begin{array}{l}\text { Delivered in } \\
\text { single or multiple } \\
\text { sessions }\end{array}$} & Module 1 & Nurturance, Understanding, and Joining \\
\hline & & Module 2 & $\begin{array}{l}\text { Breathing Retraining, Grounding Exercises, and } \\
\text { Mindfulness Meditation }\end{array}$ \\
\hline & & Module 3 & $\begin{array}{l}\text { Psychoeducation about Trauma, Grief, and the } \\
\text { Cognitive-Behavioral Model }\end{array}$ \\
\hline & & Module 4 & $\begin{array}{l}\text { Increasing Acceptance and Sense of Permission to } \\
\text { Experience Challenging Emotions }\end{array}$ \\
\hline & & Module 5 & Connecting with the Patient's Voice \\
\hline & & Module 6 & Using the EMPOWER Toolbox and Coping Rehearsal \\
\hline Phone & $\begin{array}{l}2 \text { weeks post- } \\
\text { Module } 6\end{array}$ & Booster Call 1 & $\begin{array}{l}\text { Check-in and review of psychoeducation and coping } \\
\text { skills }\end{array}$ \\
\hline Phone & $\begin{array}{l}4 \text { weeks post- } \\
\text { Module } 6\end{array}$ & Booster Call 2 & $\begin{array}{l}\text { Check-in and review of psychoeducation and coping } \\
\text { skills }\end{array}$ \\
\hline
\end{tabular}


Table 2. Module Content and Format Modifications

\section{Module 1: Nurturance, Understanding and Joining}

- Added instruction for interventionist to mention manual will be used throughout

- Added instruction for interventionist to describe the modular nature of EMPOWER

- Added question: "How are other people around you coping and how does it affect your coping?"

- Added notes for interventionist about themes of the caregiver experience (e.g., drive to focus on patient to determent of the caregiver's needs)

Module 2: Breathing Retraining, Grounding Exercises, and Mindfulness Meditation

- Added instructions for interventionist to not refer to the increased risk of PTSD for sensitivity

- Added psychoeducation and rationale for Module 2 topic

- Modified breathing, mindfulness, and grounding exercises

- Added instruction for interventionist to carefully assess appropriateness of exercises based on caregiver history of prior trauma

Module 3: Psychoeducation about Trauma, Grief, and the Cognitive-Behavioral Model

- Expanded psychoeducation on anticipatory grief and peritraumatic stress

- Added instruction for interventionist on presenting the cognitive-behavioral model

- Provided examples of Socratic questions to facilitate cognitive restructuring exercise

Module 4: Increasing Acceptance and Sense of Permission to Experience Challenging Emotions

- Changed module order from 6 to 4

\section{Module 5: Connecting with the Patient's Voice}

- Changed module order from 4 to 5

- Modified language "empty chair" to "imaginal conversation" exercise

Module 6: Using the EMPOWER Toolbox and Coping Rehearsal

- Changed module order from 5 to 6

- Added instruction for interventionist to summarize challenges that may arise in the future

- Added guidance for interventionist on how to conclude the module 
Table 3. Part 2 Surrogate decision-maker and patient characteristics $(\mathrm{N}=10)$

\begin{tabular}{|c|c|c|c|c|}
\hline \multirow[b]{2}{*}{ Characteristic } & \multicolumn{2}{|c|}{$\begin{array}{l}\text { Surrogates } \\
(n=10)\end{array}$} & \multicolumn{2}{|c|}{$\begin{array}{l}\text { Patients } \\
(n=9)\end{array}$} \\
\hline & $\mathbf{n}$ & $\%$ & $\mathbf{n}$ & $\%$ \\
\hline \multicolumn{5}{|l|}{ Age } \\
\hline 64 or younger & 8 & 80 & 3 & 33 \\
\hline 65 or older & 2 & 20 & 6 & 67 \\
\hline \multicolumn{5}{|l|}{ Gender } \\
\hline Male & 4 & 40 & 4 & 44 \\
\hline Female & 6 & 60 & 5 & 56 \\
\hline \multicolumn{5}{|l|}{ Race } \\
\hline White & 8 & 80 & 4 & 44 \\
\hline Black & 1 & 10 & 1 & 11 \\
\hline Other & 1 & 10 & 2 & 22 \\
\hline Missing & 0 & 0 & 2 & 22 \\
\hline \multicolumn{5}{|l|}{ Ethnicity } \\
\hline Hispanic & 0 & 0 & 1 & 11 \\
\hline Non-Hispanic & 7 & 70 & 5 & 56 \\
\hline Missing & 3 & 30 & 3 & 33 \\
\hline \multicolumn{5}{|l|}{ Religion } \\
\hline Christianity & 3 & 30 & 3 & 33 \\
\hline Judaism & 3 & 30 & 2 & 22 \\
\hline Other & 2 & 20 & 2 & 22 \\
\hline None & 2 & 20 & 1 & 11 \\
\hline Missing & 0 & 0 & 1 & 11 \\
\hline \multicolumn{5}{|l|}{ Education } \\
\hline Some high school & 1 & 10 & & \\
\hline High school graduate/GED & 1 & 10 & & \\
\hline Some college & 2 & 20 & & \\
\hline Undergraduate degree & 1 & 10 & & \\
\hline Graduate/professional degree & 5 & 50 & & \\
\hline \multicolumn{5}{|l|}{ Relationship to the patient } \\
\hline Son/Daughter & 6 & 60 & & \\
\hline Spouse/Partner & 3 & 30 & & \\
\hline Parent & 1 & 10 & & \\
\hline \multicolumn{5}{|l|}{$\begin{array}{l}\text { Any counseling or treatment for } \\
\text { emotional problem in the past? }\end{array}$} \\
\hline Yes & 4 & 40 & & \\
\hline No & 3 & 30 & & \\
\hline Missing & 3 & 30 & & \\
\hline
\end{tabular}


Table 4. Part 2 Post-intervention Satisfaction Questionnaire Survey Responses

\begin{tabular}{lll}
\hline Continuous items ( $\mathbf{n}=6)$ & M & SD \\
\hline $\begin{array}{l}\text { How effective did you think the } \\
\text { entire EMPOWER session was? }\end{array}$ & 8.0 & 2.3 \\
$\begin{array}{l}\text { How helpful did you find the } \\
\text { EMPOWER session(s)? }\end{array}$ & 8.0 & 2.8 \\
$\begin{array}{l}\text { It helped me to focus } \\
\begin{array}{l}\text { It helped me to make decisions } \\
\text { regarding the patient's care }\end{array}\end{array}$ & 7.2 & 3.8 \\
$\begin{array}{l}\text { It helped me to think through what } \\
\text { the patient wanted }\end{array}$ & 7.3 & 2.3 \\
$\begin{array}{l}\text { It helped make me less stressed } \\
\text { Categorical items ( } \mathbf{n}=9 \text { ) }\end{array}$ & 8.0 & 2.8 \\
$\begin{array}{l}\text { How would you rate the length of } \\
\text { this treatment? }\end{array}$ & $\mathbf{n}$ & 2.4 \\
$\quad \begin{array}{l}\text { Too brief } \\
\quad \text { Too long }\end{array}$ & 2 & $\%$ \\
$\quad$ Just right & 1 & 22.2 \\
\hline
\end{tabular}




\section{EMPOWER FOR SURROGATES OF CRITICALLY ILL PATIENTS}

Table 5. Changes in mental health symptoms over time

\begin{tabular}{|c|c|c|c|c|c|c|c|c|c|c|c|c|c|c|}
\hline \multicolumn{6}{|c|}{ Pre-intervention (T1) } & \multicolumn{3}{|c|}{$\begin{array}{c}\text { Post- } \\
\text { intervention (T2) }\end{array}$} & \multicolumn{3}{|c|}{$\begin{array}{c}\text { One-month } \\
\text { follow-up (T3) }\end{array}$} & \multicolumn{3}{|c|}{$\begin{array}{l}\text { Three-month } \\
\text { follow-up (T4) }\end{array}$} \\
\hline Measure & $\mathbf{n}$ & $\mathbf{M}$ & SD & Min & Max & $\mathbf{n}$ & Diff & d & $\mathbf{n}$ & Diff & d & $\mathbf{n}$ & Diff & d \\
\hline $\begin{array}{l}\text { Peritraumatic Distress } \\
\text { Inventory (PDI) }\end{array}$ & 9 & 17.2 & 9.8 & 7 & 33 & 8 & -1.8 & -0.24 & & & & & & \\
\hline $\begin{array}{l}\text { Patient Health } \\
\text { Questionnaire } 9 \text { (PHQ-9) }\end{array}$ & 7 & 8.7 & 4.3 & 4 & 16 & 7 & -0.1 & -0.03 & 4 & -2.3 & -0.65 & 6 & -1.2 & -0.23 \\
\hline $\begin{array}{l}\text { Generalized Anxiety } \\
\text { Disorder } 7 \text { (GAD-7) }\end{array}$ & 7 & 13.4 & 4.8 & 5 & 19 & 7 & -1.7 & -0.41 & 4 & -1.5 & -0.24 & 5 & -1.4 & -0.29 \\
\hline HADS Depression & 3 & 13.3 & 3.8 & 9 & 16 & 2 & -1.0 & 0.00 & & & & & & \\
\hline HADS Anxiety & 3 & 15.7 & 3.5 & 12 & 19 & 2 & -3.5 & -0.90 & & & & & & \\
\hline $\begin{array}{l}\text { Prolonged Grief 12/13 } \\
\text { (PG-12/PG-13)* }\end{array}$ & 10 & 35.7 & 8.1 & 21 & 48 & 9 & -0.2 & -0.03 & 6 & -3.0 & -0.45 & 7 & -6.7 & -0.94 \\
\hline $\begin{array}{l}\text { Brief Experiential } \\
\text { Avoidance Questionnaire } \\
\text { (BEAQ) }\end{array}$ & 10 & 47.4 & 12.7 & 33 & 70 & 9 & -4.3 & -0.23 & 6 & -3.0 & -0.21 & 7 & -5.0 & -0.30 \\
\hline $\begin{array}{l}\text { Distress Tolerance Scale } \\
\text { (DTS) }\end{array}$ & 9 & 11.7 & 5.5 & 6 & 20 & 8 & 0.0 & 0.00 & 6 & -1.2 & -0.23 & 7 & 0.7 & 0.14 \\
\hline $\begin{array}{l}\text { Family Decision-Making } \\
\text { Self Efficacy Scale } \\
\text { (FDMSE) }\end{array}$ & 9 & 70.7 & 9.1 & 51 & 78 & 8 & -1.4 & -0.15 & & & & & & \\
\hline $\begin{array}{l}\text { Impact of Events Scale - } \\
\text { Revised (IES-R) }\end{array}$ & 5 & 30.0 & 12.9 & 14 & 44 & & & & 4 & -6.0 & -0.25 & 4 & -2.00 & -0.15 \\
\hline
\end{tabular}

${ }^{*}$ All participants were administered PG-12 at baseline and were administered PG-12 or PG-13 based on patient vital status at following timepoints.

† First administered post-intervention (T2) 